\title{
Physical Punishment in Secondary Schools Students and Its Relation with Anxiety Level
}

\author{
${ }^{1}$ Rehab Hani Elkazaz; ${ }^{2}$ Abeer Elsayed Berma ; Inas Abd ELstar Ebied \\ ${ }^{1}$ Lecturer of Pediatric Nursing, Faculty of Nursing, Port Said University, Egypt \\ ${ }^{2},{ }^{3}$ Lecturer of Psychiatric Nursing and Mental Health, Faculty of Nursing, Port Said University, Egypt
}

\begin{abstract}
Background: physical punishment is the physical punitive measures of parents or teachers against children or adolescent with devastating consequences when bordering on child abuse.

Method: A descriptive research design aiming to assess the relationship between physical punishment and anxiety among adolescents. This study was conducted at secondary schools. The study sample consisted of $\mathbf{6 0 0}$ students. The data was collected through the two tools were used to collect the necessary data to achieve the aim of the study, they were physical punishment interview tool and anxiety scale.

Results: The results revealed that the majority of secondary schools students at study sample were exposed to physical punishment at home, while more than half of them were exposed to physical punishment at school, but all levels of anxiety were increased among adolescents either exposed or not exposed to physical punishment in home and school. Conversely, In both cases the reverse no statistically significant correlation was found. While anxiety score predicted increased among female. Our study provides important new insights into the development of anxiety levels in adolescents regardless their exposure or not exposure to physical punishment. This study extends and suggests that the teachers shall be encouraged to avoid physical punishment as well as psychologically aggressive disciplinary methods and must use alternative forms of correction of students misbehavior. Provide parents and teachers information on adolescent development and behavior management through workshops, library books and brochures.
\end{abstract}

Keywords: Adolescents, Anxiety, Physical Punishment

\section{Introduction}

Physical punishment is a violation of children's rights. International human rights law is clear that children have a right to legal protection from all physical punishment in all settings of their lives (1). Physical punishment has been linked with poor psychological development of children and adolescents (2).

Hadi (3) describes physical punishment as the physical force applied on children by parents, guardians, teachers to control and discipline the child. physical punishment includes methods such as hitting, slapping, pinching, by using items such as belts, sticks, pins etc. Children are also made to remain in painful body postures or prohibited to eliminate urine or stool (4) or pencils are placed between student's fingers and pressed to create pain. Still today, it is a common method of disciplining children around the globe and there is a very delicate line between physical abuse and disciplining a child (5). Physical punishment has been linked with poor psychological development of children and adolescents (2). Anxiety represents one of the most common problems in child and adolescent at the present. Anxiety is an uncomfortable feeling of apprehension or dread that occurs in response to internal or external stimuli and can result in physical, emotional, cognitive, and behavioral symptoms (6).

Aim of the study:

To assess the relationship between physical punishment and anxiety level among adolescents.

Research Questions :

1- Compare between the students exposed and not exposed to physical punishment and their levels of anxiety? 2 - Does a correlation between males and female students regarding anxiety level?

\section{Design and setting:}

\section{Materials and Method}

The study was conducted in eight schools in Port Said city using a descriptive research design. It included eight secondary schools, equally for boys and girls.

Sample:

This comprised school children from secondary grades selected by stratified cluster random sampling. Port Said schools were classified into four strata according to gender (boys/girls) and educational. Two schools were randomly selected from each of the four strata, for a total sample of eight schools. Within the selected 
schools, classes constituted the clusters. Two or three clusters were randomly selected from each selected school to fulfill the required sample size. The sample size was calculated to estimate a prevalence rate of physical punishment of $39 \%$ (7) with $4.5 \%$ absolute precision, a design effect 2, at $95 \%$ level of confidence. After correction for a dropout rate of about $10 \%$, the required sample size was 600 students.

\section{Tools of data collection:-}

TOOL I: Sociodemographic Questionnaire:

\section{1. physical Punishment Interview Tool}

This is a structure interview schedule that was developed by the researcher after a thorough review of literature to collect data about exposure to physical punishment at home and school, it is divided into three parts:

Part (1):

The first part was used to collect data about socio-demographic characteristics of the studied subjects such as school of enrolment, sex, age, family structure, , and parent education.

\section{Part (2):}

The second part was developed to collect data about the exposure of the students to physical punishment at home, it contained 8 questions to be answered by "Yes" or "No". these questions probed areas such as; punishment at home, methods of punishment such as "beating", "biting", "punitive posture"...etc, causes of punishment, instruments and ways of punishment, if the child get hospital care or seeking medical advice related to physical injury.

Part (3):

The third part was developed to collect data about the exposure of the students to physical punishment at school, it contained 8 questions to be answered by "Yes" or "No". these questions probed areas such as punishment at school, methods of punishment such as, beating, punitive posture, pinching...etc, area of beating such as body, face, hand, foot....etc, causes punishment, instruments used if the child get hospital care of seeked medical advice related to physical injury.

\section{Taylor anxiety scale:}

An inventory for measuring anxiety. These anxiety scale was modified and translated to Arabic Language by Ghally (8). The purpose of this scale is to assess the anxiety level as expressed by individuals. This scale comprises of 49 items to be answered by "Yes" or "No". Total score ranged from 0 to 49, with higher scores indicative of greater severity of self reported anxiety as follows:

- $\quad$ - 22 : No or Mild Anxiety.

- 22 - 26: Moderate Anxiety.

- 27 or more: Severe Anxiety.

Validity of Anxiety Taylor Scale:

Correlations with clinician ratings of anxiety using the revised anxiety Taylor scale range from 0.52 to 0.80 (9).

Reliability of Anxiety:

Internal consistency of anxiety Taylor scale, the test - retest coefficient was found to be 0.82 over 5 months and for the longer period (9).

Pilot Study:

The developed tool was reviewed by a panel of experts in nursing and medicine. Then, a pilot study was carried out on a sample of adolescents from other schools to test the clarity and reliability of the tool and feasibility of the study. The tool reliability was tested. Needed modifications were done in the form of rephrasing of some items. The pilot subjects were not included in the main study sample.

\section{Fieldwork:}

The required official steps were taken to get the approval of carrying out the study from the local Directorate of Education. Letters of agreement were issued to the headmasters of selected schools from the Directorate to conduct the study, and asking for cooperation with the researchers. Meetings were held with individual headmasters, where the researchers explained the purpose of the study. The researchers met with students in classrooms, explained to them the purpose of the study, and distributed the questionnaire forms to be completed.

\section{Ethical Considerations:}

Letters were addressed through schools to the parents of students explaining the study goal and procedures, and the rights to refuse or withdraw at any time. Confidentiality of the data was ensured and the collection tools were anonymous. Professional advice was provided to any affected student whenever needed. The field work was carried out from November 2015 to May 2016.

Data analysis: Data were using descriptive statistics in the form of frequencies and percentages, as well as means and standard deviation. Categorical variables were compared using chi-square test. Whenever the expected values in one or more of the cells in a $2 \times 2$ tables was less than 5.Statistical significance was considered 
at $\mathrm{p}$-value $<0.05$.

\section{Results}

Table (1) shows the socio-demographic of adolescence and physical punishment. As regard age, the half of the studied subjects $(50 \%)$ were in the age group 15years. Concerning their sex the more than half of the adolescence were females $(55.6 \%)$. Concerning their exposure to physical punishment the majority of them were exposed to physical punishment at home, while more than half of them (78.0\%) were exposed to physical punishment at school. Finally, 39.2\% of adolescence in the study sample were not exposed to physical punishment.

Table (2) Socio-demographic characteristics of parents as perceived by students regarding their age and education. Illustrates that; more than one third of both father and mother (35.2\%, 36\% respectively) have secondary education.

Table (3) physical punishment at home and school a s stated by the students in the study sample. The table revealed that, the majority of students (82.8) suffered from physical punishment at home while only $3.82 \%$ of them received medical intervention. $78.0 \%$ of students exposed to physical punishment at school and $1.44 \%$ of them received medical intervention.

Table (4) Pattern of physical punishment and the ways of beating at home as perceived by students.

regarding the methods of physical punishment most of students $(90.5 \%)$ were beaten and least of them $(1.2 \%)$ were kicked by feet. Concerning the ways of beating slightly less than half of students $(46.7 \%)$ hitting all body followed by slapping $(40.2 \%)$.

Table (5) Pattern of physical punishment at schools as perceived by students. illustrates that, Pattern of physical punishment at schools. the majority of students $(88.7 \%)$ punished by hitting the hands, less than half of them $(46.4 \%)$ have punitive posture at schools.

Table (6): Comparison between the students exposed and exposed to physical punishment and levels of anxiety. The findings showed that, all levels of anxiety were increased among adolescents either exposed or not exposed to physical punishment in home. There is statistically significant relation between students exposed and those who do not exposed to physical punishment at school and level of anxiety ( $\left.\mathrm{p}=0.05^{*}\right)$.

Table (7): Correlation between males and female students regarding anxiety score. The findings showed that, anxiety score predicted increased among female. Conversely, In both cases the reverse no statistically significant correlation was found.

Table (1) Socio-demographic characteristics of adolescence and physical punishment in the study sample $(n=600)$.

\begin{tabular}{|l|l|l|}
\hline Characteristics & Frequency & Percent \\
\hline Age (years): & 300 & \\
$\quad 15-$ & 248 & 50 \\
$16-$ & 52 & 41.3 \\
$17-18$ & & 8.6 \\
\hline Gender: & 266 & \\
Male & 334 & 44.4 \\
Female & 497 & 55.6 \\
\hline Exposed to punishment: & 486 & 82.8 \\
At home & & 78.0 \\
At school & 235 & 39.2 \\
\hline Not exposed to punishment & \\
\hline
\end{tabular}

Table (2): Socio-demographic characteristics of parents as perceived by students regarding their age and education.

\begin{tabular}{|l|r|r|}
\hline Characteristics & $\begin{array}{l}\text { Frequency } \\
\text { No }\end{array}$ & $\begin{array}{l}\text { Percent } \\
\text { \% }\end{array}$ \\
\hline Father's level of education & 54 & 9.0 \\
Illiterate & 41 & 6.8 \\
Read\& write & 84 & 14.0 \\
Primary education & 66 & 11.0 \\
Preparatory education & 144 & 24.0 \\
Secondary education & & \\
Bachelor's degree or higher & & 19.0 \\
\hline mother's level of education & 114 & 5.5 \\
Illiterate & 33 & 18.0 \\
Read\& write & 108 & 10.0 \\
Primary education & 60 & 36.0 \\
Preparatory education & 216 & 11.5 \\
Secondary education & 69 & 81.0 \\
Bachelor's degree or higher & & \\
\hline Family structure & 486 & \\
Together & 53 & \\
Separated & & \\
\hline
\end{tabular}




\begin{tabular}{|l|r|r|}
\hline Widow & 61 & 10.2 \\
\hline
\end{tabular}

Table (3) physical punishment at home and school a s stated by the students in the study sample ( $\mathrm{n}=600)$.

\begin{tabular}{|l|l|l|}
\hline physical punishment & Frequency & Percent \\
\hline At Home: & & \\
Exposed & 497 & 82.8 \\
Not exposed & 103 & 17.2 \\
Medical intervention & 19 & 3.82 \\
\hline At school: & & \\
Exposed & 486 & 78.0 \\
Not exposed & 132 & 22.0 \\
Medical intervention & 7 & 1.44 \\
\hline
\end{tabular}

Table (4): Pattern of physical punishment and the ways of beating at home as perceived by students.

\begin{tabular}{|c|c|c|c|}
\hline & Items & No & $\%$ \\
\hline \multicolumn{4}{|c|}{ The Methods of Corporal Punishment at Home $(n=497)$ : } \\
\hline & ... Beating & & \\
\hline & Punitive posture & 450 & 90.5 \\
\hline & Pinching & 132 & 26.6 \\
\hline & Biting & 122 & 24.5 \\
\hline & Throw by instrument & 107 & 21.5 \\
\hline & Tied with rope & 64 & 12.9 \\
\hline & Burn & 42 & 8.5 \\
\hline & Kick by feet & 28 & 5.6 \\
\hline & & 6 & 1.2 \\
\hline \multicolumn{4}{|c|}{ The Ways of Beating at Home $(n=450)$ : } \\
\hline \multirow{6}{*}{ Hitting the feet } & Hitting the body & 210 & 46.7 \\
\hline & Slapping & 181 & 40.2 \\
\hline & Hitting the hands & 33 & 7.3 \\
\hline & & 16 & 3.5 \\
\hline & Hitting by shoes & 7 & 1.6 \\
\hline & Strike the head on the wall & 3 & 0.7 \\
\hline
\end{tabular}

Table (5): Pattern of physical punishment at schools as perceived by students.

\begin{tabular}{|l|l|l|}
\hline \multicolumn{1}{|c|}{ Items } & \multicolumn{1}{|c|}{ No } & \multicolumn{1}{|c|}{$\%$} \\
\hline The methods of corporal punishment at school : & & \\
Hitting the hands & 415 & 88.7 \\
Punitive posture & 217 & 46.4 \\
Slapping & 79 & 16.9 \\
Hitting the feet & 36 & 7.7 \\
Hitting the buttocks & 16 & 3.4 \\
Tied with rope & 3 & 0.6 \\
Put pen between fingers & 3 & 0.6 \\
Kick by feet & 3 & 0.6 \\
\hline
\end{tabular}

Table (6): Comparison between the students exposed and exposed to physical punishment and levels of anxiety in the study sample $(\mathrm{n}=600)$.

\begin{tabular}{|c|c|c|c|c|c|c|c|c|c|}
\hline \multirow{3}{*}{ Physical Punishment } & \multicolumn{6}{|c|}{ Levels of Anxiety } & \multirow{3}{*}{ Total } & \multirow{3}{*}{$\mathbf{X}^{2}$} & \multirow{3}{*}{ P-Value } \\
\hline & \multicolumn{2}{|c|}{ Mild } & \multicolumn{2}{|c|}{ Moderate } & \multicolumn{2}{|c|}{ Severe } & & & \\
\hline & No & $\%$ & No & $\%$ & No & $\%$ & & & \\
\hline At Home: & & & & & & & & & \\
\hline Exposed & 138 & 27.7 & 186 & 37.4 & 173 & 34.6 & 497 & 32.96 & 0.192 \\
\hline Not exposed & 38 & 36.9 & 33 & 32.0 & 32 & 31.0 & 103 & & \\
\hline At school: & & & & & & & & & \\
\hline Exposed & 129 & 27.6 & 170 & 36.3 & 169 & 36.1 & 468 & 4.22 & $0.05^{*}$ \\
\hline Not exposed & 48 & 36.4 & 49 & 37.1 & 35 & 26.5 & 132 & & \\
\hline
\end{tabular}

Table (7): Correlation between males and female students regarding anxiety score in the study sample $(\mathrm{n}=600)$.

\begin{tabular}{|c|c|c|c|c|c|c|}
\hline & \multicolumn{2}{|c|}{ Males } & \multicolumn{2}{|c|}{ Female } & \multirow{2}{*}{$\begin{array}{l}\text { Sig. } \\
\text { Test }\end{array}$} & \multirow[b]{2}{*}{ P-Value } \\
\hline & No & $\mathbf{X}+\mathbf{S D}$ & No & $\mathrm{X}+\mathrm{SD}$ & & \\
\hline Anxiety Score & 266 & $23.81+6.56$ & 334 & $24.63+6.27$ & $t=1.54$ & 0.123 \\
\hline
\end{tabular}

\section{Discussion}

While the reviewed studies provided hardly any evidence for beneficial effects of physical punishment, the evidence for the potential of doing harm is strong and compelling. Research findings are consistent in relation to associations with increased childhood aggression and antisocial behaviors, which carry over into adulthood, and the especially worrying risk of escalation into physical abuse (10).The results of the current study revealed that, the majority of students suffered from physical punishment at home and schools. This result was not surprising knowing that in the Egyptian parents and educators tend to support the use of physical 
punishment for discipline and education, they can also be related to the increased social stressors and violence noticed recently in the community(11). Also, one of the most commonly practiced strategies used by parents to alter bad behavior of their children is physical punishment, this study agreement with The study by (12) revealed that all children had experienced both physical and emotional abuse.Further investigations, showed that it was the perceived threat from parental physical punishment that was more harmful than the punishment itself - possibly because children's feelings of threat result in heightened stress levels (13).Furthermore, other negative outcomes that were shown to be related to physical punishment are parent-child conflict, adult mental illness and adult substance abuse. One study suggested links with a range of adult physical health outcomes (14). Various studies concluded that the parents' level of education is considered an important risk factor for child abuse. Abusing parents tend to be illiterate or less educated (15). The present study revealed the more than one third of both father and mothers have secondary education which might be due to lack of parenting skills. The parents and educators use physical punishment as an educational and disciplinary tool (11). This explains the result in the current study it was noticed that the prevalence of physical abuse. The hitting represents the most common experiences in the current study.

The current study reported no gender difference for physical punishment as was reported by (16). On the other hand; (17) found that females were at greater risk of victimization for physical and psychological abuse.1The finding of the present study showed that, the female anxiety score predicted increased, however no statistically significant correlation was found. This result may be attributed to the differences in brain chemistry may account for at least part of these differences. The brain system involved in the fight-or-flight response is activated more readily in women and stays activated longer than men, partly as a result of the action of estrogen and progesterone. In addition to, women go to the doctor and/or seek counseling more frequently than men, and consequently, are diagnosed with having an anxiety disorder more often.Gender was also found to be significantly associated with examination-related anxiety and psychiatric caseins. That is, female students experience more examination-related anxiety and psychiatric caseins than their male counterparts. This confirms previous findings that adolescent girls report a greater number of worries, more separation anxiety, and higher levels of generalized anxiety than do boys of the same age (18). (19) Stated that, higher anxiety among female students in Bengali Medium schools in India. These results are supported by (20) who mentioned that, females had a higher prevalence of anxiety than males in both middle and secondary schools. The prevalence of anxiety did not vary substantially among schools for either middle or secondary schools.

Furthermore, anxiety disorders were associated with a greater illness burden in women than in men, particularly among European American women and to some extend also among Hispanic women. These results suggest that anxiety disorders are not only more prevalent but also more disabling in women than in men (21).

In contradiction with this result, (22) found that, the mean anxiety score for adolescent boys (24.06) was found to be slightly higher than that for adolescent girls (22.55) with $20.1 \%$ of boys and $17.9 \%$ of girls also found to be suffering from high anxiety. Regarding the levels of anxiety, the findings of the current study noted that, all levels of anxiety were increased among adolescents either exposed or not exposed to physical punishment in home and school. However no statistically significant correlation was found in home. May be attributed to the fact that anxiety is one of the most common mental health problems. Adolescence is the core risk phase for the development of anxiety symptoms and syndromes, ranging from transient mild symptoms to full-blown anxiety disorders regardless exposure or not exposure to physical punishment. In addition to increased levels of anxiety and depression, today's teenagers are more likely to be in education and less likely to be in paid employment than adult leading to a longer and less structured period of adolescence. There is statistically significant correlation was found in school.This result support by $(\mathbf{2 3})$ who found that there was appositive relation between severe anxiety and physical punishment at school.

A later longitudinal study presented evidence of a causal link between corporal punishment and internalized behavior among boys and girls (24). Its findings showed that girls, mild or severe levels physical punishment predicted increased levels of anxiety and depression. Conversely, among boys, only severe physical punishment significantly predicted internalized disorders, such as anxiety and depression. In both cases the reverse relationship was not significant, strengthening the evidence identifying the causal factor in the relationship between these variables.In contrast to the findings (25) stated that the child abuse, domestic violence, and both in combination (i.e., dual exposure) increase a child's risk for internalizing and externalizing outcomes in adolescence. When accounting for risk factors associated with additional stressors in the family and surrounding environment, only those children with dual exposure had an elevated risk of the tested outcomes compared to non-exposed youth. However, while there were some observable differences in the prediction of outcomes for children with dual exposure compared to those with single exposure (i.e., abuse only or exposure to domestic violence only), these difference were not statistically significant.Thus, it is of great importance to assess the relationship between physical punishment and anxiety among adolescent, in order to identify and minimize as much as possible the factors of anxiety, provide appropriate management that improve anxiety among adolescent and offer them opportunities for personal social fulfilling in their lives. 


\section{Strengths, Limitations, and Conclusions}

The present study is the first to examine physical punishment in secondary schools students and its relation with anxiety level. In doing so, we included a variety of secondary schools in Port Said city. Important additional strengths of the study are the use of a descriptive design and the fact that our measure of anxiety level and physical punishment were based on self-report rather than parental or teacher reports. This strategy reduced the risk of bias compared to parental or teacher reports.Despite these strengths, our study also has several limitations. A first limitation is the relatively small sample size, which while sufficient to detect significant twoway interactions, did not offer enough statistical power to detect significant correlation. In regard to sample characteristics, generalization from secondary school students to other adolescents in the different schools may be limited. A further limitation concerns the fact that, given that anxiety levels may be influenced by genetic and environmental factors. There has been limited research on physical punishment and its relationship to the specific emotional aspects of anxiety in children.

A final limitation is that the limited number of anxiety items provided only a general evaluation of anxiety. Future studies need to replicate the present findings using a more extensive measure of anxiety symptoms with additional reporting sources. Notwithstanding these limitations, our study provides important new insights into the development of anxiety levels in adolescents regardless their exposure or not exposure to physical punishment. However, results from the present study suggest that anxiety score predicted increased among female.

\section{Recommendations}

\section{Based on the findings of the present study, the following recommendations are suggested:}

1- This study extends and suggests that the teachers shall be encouraged to avoid physical punishment as well as psychologically aggressive disciplinary methods and must use alternative forms of correction of students misbehavior.

2- Mass media is one of the most effective sources to highlight the issues of major concern, anxiety among adolescents. In this context, media should be involved obsessively to strive for elimination of such a menace in shape of telecasting different programs, talk shows, documentaries, articles in newspapers and magazines etc.

3- Involving parents may reduce the risk of anxiety between adolescent by changing certain aspects of the family environment that can maintain anxiety symptoms in youth such as high parental control, parental anxiety, and parental reinforcement of avoidant coping strategies.

4- Further studies are recommended to examine the characteristics and risk factors of all types of abuse. Psychological support programs should be directed towards abused children.

\section{References}

[1]. Committee on the Rights of the Child (2006): General Comment No. 8: The right of the child to protection from corporal punishment and other cruel or degrading forms of punishment (arts. 19; 28, para. 2; and 37, inter alia) (CRC/C/GC/8).

[2]. Straus M, Paschall L (2009): Corporal Punishment by Mothers and Development of Children's Cognitive Ability: A Longitudinal Study of Two Nationally Representative Age Cohorts. Journal of Aggression, Maltreatment \& Trauma, 18, 459483.http://dx.doi.org/10.1080/10926770903035168

[3]. Hadi H (2015): Corporal Punishment: Heralding Discipline or Psychological Ill Health? JPMS Medical Blogs. jpmsonline.com. Retrieved from http://blogs.jpmsonline.com/2014/10/28/corporal-punishment-heralding-discipline-or- psychological-ill-health .

[4]. Gershoff E (2008): Report on Physical Punishment in the United States: What Research Tells Us About Its Effects on Children. Columbus OH: Center for Effective Discipline.

[5]. Zolotor A (2014): Corporal punishment. Pediatric Clinics of North America, 61(5), 971.

[6]. Yaffe Y, Burg D (2014): Corporal Punishment as a Parental Practice and Anxiety in Pre - adolescent Children, Journal of Social Science Studies, 1 (2): 2329- 9150.

[7]. Abolfotouh M (2009): "Corporal punishment: Mother's disciplinary behavior and child's psychological profile inAlexandria, Egypt", Journal of Forensic Nursing 5, 5-17.

[8]. Ghally M ( 1986): Comparative study for neurotic and delinquent about organization of personality , Unpublished Doctorate Disseration, Faculty of Education, AinShams University, Egypt , 238243.

[9]. Cooper C., and Pervin L (1998): Personality critical concept in psychology , Apersonality scale of manifested anxiety . journal of abnormal and social psychology , $48: 3-11$.

[10]. Bunting L, Webb M, Healy J (2008): The 'smacking debate' in Northern Ireland - messages from research. Northern Ireland Commissioner for Children and Young People.

[11]. Alyahri A, Goodman R (2008): Harsh corporal punishment of Yemeni children: occurrence, type and associations. Child Abuse Neglect . 32:766-73.

[12]. Sameh S, Rania K. , Rehab I., Ghada F (2016): Emotional, physical and sexual abuse and its psychological impact in children. International Journal of Contemporary Pediatrics, 3( 3): 760-767.

[13]. Mulvaney M, Mebert C (2010): Stress Appraisal and Attitudes Towards Corporal Punishment as Intervening Processes Between Corporal Punishment and Subsequent Mental Health. Journal of Family Violence, 25(4), 401-412.

[14]. Afifi T, Mota N, MacMillan H, Sareen J (2013): Harsh Physical Punishment in Childhood and Adult Physical Health. Pediatrics, 132(2), E333-E340. 
[15]. MacMillan H, Tanaka M, Duku E, Vaillancourt T(2013): Child physical and sexual abuse in a community sample of young adults: Results from the Ontario Child Health Study. Child Abuse Neglect.;37:14-21.

[16]. Christoffersen M., Armour C., Lasgaard M., Andersen T., Elklit A (2013 ): The prevalence of four types of childhood maltreatment in Denmark.Clin Pract Epid Mental Health. 9:149-56.

[17]. Al-Eissa M, AlBuhairan F, Qayad M, Saleheen H, Runyan D, Almuneef M (2015): Determining child maltreatment incidence in Saudi Arabia using the ICAST-CH: A pilot study. Child Abuse Neglect.;42:174-82.

[18]. Weiss D, Last C (2001): Developmental variations in the prevalence and manifestations of anxiety disorders. The developmental psychopathology of anxiety (pp. 27-42). Oxford: Oxford University Press.

[19]. Gershoff E., Gorgan-Kaylor A., Lasford J., Chang L., Zelli, A., Deater-Deckard, K., Dodge K (2010): Parent Discipline Practices in an International Sample: AssociationsWith Child Behaviors and Moderation by Perceived Normativeness. Child Development, 81(2), 487-502.

[20]. Tramonte L, Willms D (2010): The prevalence of anxiety among middle and secondary school students in Canada. Can J Public Health. Nov-Dec;101 Suppl 3:S19-22.

[21]. McLean P, Asnaani A, Litz B, Hofmann S (2012): Gender Differences in Anxiety Disorders: Prevalence, Course of Illness, Comorbidity and Burden of Illness. J Psychiatr Res. 2011 Aug; 45(8): 1027-1035.

[22]. Deb S, Chatterjee P, Walsh K ( 2010): Anxiety among high school students in India: comparisons across gender, school type, social strata, and perceptions of quality time with parents. Australian Journal of Educational and Developmental Psychology, 10(1), $18-31$.

[23]. Fergusson D, Boden J, Horwood L ( 2008): Exposure to childhood sexual and physical abuse and adjustment in early adulthood. Child Abuse \& Neglect 32 607-619.

[24]. Xing X, Wang W (2013): Sex differences in the reciprocal relationships between mild and severe corporal punishmentand children's internalizing problem behavior in a Chinese sampleJournal of Applied Developmental Psychology, 34, 916.http://dx.doi.org/10.1016/j.appdev.2012.09.004.

[25]. Carrie A, Moylan 1, Todd I, Herrenkohl 1 Cindy Sousa 1 Emiko A, Tajima 1 Roy C, Herrenkoh l, Jean R (2010): The Effects of Child Abuse and Exposure to Domestic Violence on Adolescent Internalizing and Externalizing Behavior Problems Journal of Family Violence. Jan; 25(1): 53-63. 